\title{
Classroom-Produced Journals: Integrating Undergraduate Research into the Curriculum and Publishing Scholarship through the Institutional Repository
}

\author{
A. Miller \\ Middle Tennessee State University \\ a.miller@mtsu.edu
}

Keywords: undergraduate research, institutional repository, library publishing, active learning, online publishing, student journal, collaboration, journal publishing

Writing skills are an important part of a student's academic success. Literature suggests that incorporating research into the undergraduate curriculum will not only strengthen their academic writing, but also the quality of the academic experience (Ho, 2011). Thus, allowing students to be active participants through an entire research lifecycle will not only enhance the curriculum but increase student engagement. The research lifecycle, including publication, requires both individual and group based efforts and both are essential to producing a classroom-produced journal.

Class-based projects such as this can introduce students to methodologies surrounding original research (Matty, 2005). For publishing research, this includes identifying, evaluating and analyzing an issue and then interpreting and disseminating the results. Not only will students still write the traditional student research paper individually, but the class as a group, will create a professional journal issue that is preserved and indexed in a real online repository. Many universities already have such resources, called an institutional repository (IR). The IR captures and preserves the scholarly output of the university and are commonly provided by the library as an online publishing service. (Ho, 2011).

The Scholarship of Teaching and Learning (SOTL) field recently reported on how active learning experiences are superior to passive models of instruction which include opportunities for, and high levels of, student engagement, interaction with peers and student-teacher communication (Ellison and $\mathrm{Wu}, 2008$ ). Integrating undergraduate research into the curriculum and aided by the dissemination and discoverability of that research through a published journal, is a way of developing student engagement and closely links teaching and research (Stone et al., 2016). This connection of the learning process gives students a new perspective to academic writing.

In Stone et. al (2016), literature from the U.K. and U.S. were reviewed to determine the use and benefits of student journals. Many studies show writing skills have improved due to the back-and-forth nature of journal writing, an aspect of the publication process that is not typically a part of the curriculum or assignment. "The process of preparing and repurposing work for submission challenges students to strive for the highest academic standards of quality and originality as well as giving them valuable experience in the publishing process” (153). Other studies found students favored reviewer feedback and found it more useful than that from their assignments, that the act of writing for publication, rather than writing assignments, encourages students to work harder for an authentic audience (publication) rather than a grade or traditional assignment (Stone et. al, 2016; November, 2010). At the same time, this gives students a sense of ownership of an authored work and allows them to identify as a researcher. Other student benefits 
of the journal production process include a sense of achievement, heightened understanding of research, employability by adding professional content to a student's resume (Stone et. al, 2016) and is beneficial to their intellectual growth (Ho, 2011).

This article describes how an upper level undergraduate course can enhance the student experience and academic output by creating a professional journal as the semester's culminating class-project. There are many benefits to a class producing and experiencing the research lifecycle through a genuine publication:

- Students feel pride in their journal being accessible online, in catalogs, search engines, etc., where their work is discoverable by others

- Students gain a sense of ownership of their individually authored works that pass the peerreview and editorial decision process of the journal

- Identify with being more than just a student, but also a researcher, editor, reviewer, author, etc.

- Develop a heightened sense of the research and publication process

- Stimulates higher quality research due to competitive selection of articles to be published

\section{Making It Work}

With the rise of institutional repositories and the emergence of library publishing services, there are numerous opportunities for collaboration among the library and faculty in publishing student research journals (Stone et. al, 2016). The existence of a library publishing platform is optimal but not required. If a university does not have open access publishing resources, for example a journal hosting service or an institutional repository, the instructor can still disseminate the class journal via a website or blog but may lose the cataloging, indexing, ISSN and preservation capabilities that the library service provides.

Begin the project by speaking with the institutional repository manager, often times this is a librarian. Ask about the resources available for your project, and the steps and processes that should be followed. It is also suggested to work with the librarian on incorporating a research lifecycle and publication lesson to be taught by the librarian (or other expert) to help instill background knowledge for the students. For example, the librarian could discuss open access or copyright issues that affect research publication, thus educating the students and faculty member on policies and practices that optimize the journal's contribution to knowledge sharing; and prepares students for how to handle future publishing questions (Ho, 2008) including other uses of the institutional repository (which includes the publication of electronic thesis and dissertations). This session with the librarian should take place at the beginning of the semester and reinforced throughout the rest of the semester as needed by the instructor.

Typically students are required to select and write a research paper on a course related topic throughout the semester. In the beginning, students pick topics, collect data, review literature and draft their papers. This process is still the same and is required to create a culminating class journal. The main difference among this traditional research paper assignment and the journal is seeking journal article submissions. The student is to be graded on the research paper; but additionally encouraged to submit it for review to the journal. Not all submissions will be accepted so it is competitive like a real journal. And submitting an article to the journal does not affect the grade on the research paper assignment. They are not linked. This allows the students to choose whether to participate in the class journal project as an author. However, whether the student submits an 
article for review or not, they will play a role in the journal production process as an editor or peer reviewer.

Both student roles, as an editor or peer reviewer, will be a graded assignment. Therefore, all students have an incentive to follow the assignment guidelines for practicing in journal editorial roles that include objective reasoning, assessment and constructive feedback for which the delivery and quality of that role will be graded. This level of participation is a means to prepare students for real world experiences that are anticipated in job performance or future academic coursework. If a student serves as an editor, the student will not perform peer review but all students must still submit the research paper for a grade. All students have the option to additionally submit that paper for publishing consideration by the journal which is not graded.

\section{Process}

The instructor is the journal manager and designates certain student roles: editor-in-chief, section editor and layout editor and collectively they make up the journal's editorial board (alternatively, the class could vote on the makeup of these roles and additional roles could be added). The three student editors work together with the journal manager (instructor) to decide the title and scope of the journal and the number of desired articles (including a maximum number for publication). With the exception of the student editorial roles, all students in the course will be peer reviewers, each student reads and comments on at least two other student articles. The instructor should give students guidance on how to provide constructive criticism (Ellison \& Wu, 2008) prior to the peer review process. This includes how to write comments intended for the author and comments on the paper that are intended for the journal manager and editor only, which includes whether the paper is a good fit for the journal.

This peer review process happens before the research paper is turned in for a grade by each student. This way, the student benefits from the reviewer comments, allowing for any adjustments to be made (if elected) before turning in the research paper assignment for a grade. Additionally, it isn't until after the review comments and submission of the research paper assignment that the student decides whether to submit it for further review to the class journal for possible publication.

The next stage of the journal publication process is for the student section editor to collect all papers submitted for further review. This includes reviewing the peer-reviewed comments that were documented for each research paper submitted. The student section editor then accesses which articles are suited for publication based on the scope of the journal and explains the results to the editor-in-chief. Together, the editor-in-chief and section editor then rank the articles that fit the scope of the journal and decide which articles to accept since it is possible that not all can be accepted due to the limits previously established. For articles that may be acceptable but need a little more work, the editor-in-chief can provide advice and ask the author to resubmit for review once changes are made. The results are then presented to the journal manager for final approval of the selection. Once approved, the journal manager notifies the authors of their acceptance or rejection and accepted articles move to the layout production process.

The layout editor is given all the accepted articles and creates a uniform look for the journal. This can be done in a text editor (Libre Office, MS Word) or if the student layout editor has sufficient skills the layout can also be created in software with more robust features like Adobe Illustrator. The layout editor, in addition to adding the articles and corresponding pages numbers, will also create a table of contents, journal information page, cover page and logo. The journal manager will also supply the layout editor with a foreword or introduction to be placed within the 
journal issue. Once these steps are complete, all the student editors and the journal manager will review for accuracy and completeness.

Upon approval from the entire editorial board, the journal issue is ready for submission to the institutional repository. The journal manager can then submit the journal to the institutional repository for inclusion. The library will add the metadata to the record so it is discoverable, this includes the journal name, editor names, author names and article titles, the class name, year of publication, issue and volume number, etc. The library may also submit an ISSN application, requesting an international serial number to be associated with this journal (for current and future course issues), making it an official publication. This concludes the process for integrating undergraduate research into the curriculum as depicted in the Appendix.

\section{Results and Future Implications}

The launch of the official publication, including the permanent URL for the journal, can be shared via email with students in the course and the campus community. The student authors can keep track of statistics regarding their published article with the statistics feature of the institutional repository. The most widely used institutional repositories are Digital Commons (http://digitalcommons.bepress.com) and DSpace (http://www.dspace.org), both of which have statistics features that show how many times a journal issue or individual article is viewed. For those students who decided not to submit their research for further review, or for those whose articles were rejected, still benefit by being a part of the peer-review process and learning about open access, copyright and the benefits of using an institutional repository for publishing student work from the librarian. From this class-produced journal, all students gain experience in the research and publication lifecycle and further increase their awareness on the value of writing for an academic and professional audience beyond a graded assignment.

The class-produced journal is intended for upper level undergraduate courses that already have a research paper assignment in the curriculum. However, this could also be applied to a graduate level course. Another option to consider in the future, once the instructor is comfortable with using the institutional repository as the publishing platform, is using a journal hosting platform. This is also a service provided by most academic libraries but open source software for it can also be installed locally on the instructor's computer. For this, Open Journal Systems (https://pkp.sfu.ca) is recommended since it is open source and well documented by its developers. There is a learning curve to using this software so it is recommended for advanced courses and with library collaboration. The benefit to using a journal hosting software program is the editorial workflow and communication system that is built into the software, as well as the possibility of publishing in HTML in addition to PDF.

Anecdotal evidence suggests students serving in an editor role are more inclined to pursue further publishing opportunities and use this class-produced journal as evidence to enhance their resume or portfolios for graduation requirements and when applying for employment or graduate school admissions. Both students in the editor and peer review roles exhibit behaviors described as benefits to a class producing a genuine publication earlier in this paper. This engagement with the publishing lifecycle, instructor, librarian and student editorial team collectively exuberates a high impact practice for student learning and engagement. It is also a sustainable practice due to the library’s involvement and expertise in managing the indexing, cataloging, journal status, discoverability and maintenance of the journal for the instructor who can focus on teaching the course content and facilitating the editorial management 
of the publishing lifecycle. A collaborative approach such as this not only enhances the undergraduate curriculum but also increases student engagement with active learning experiences.

\section{Appendix. Classroom-Produced Journal Process}

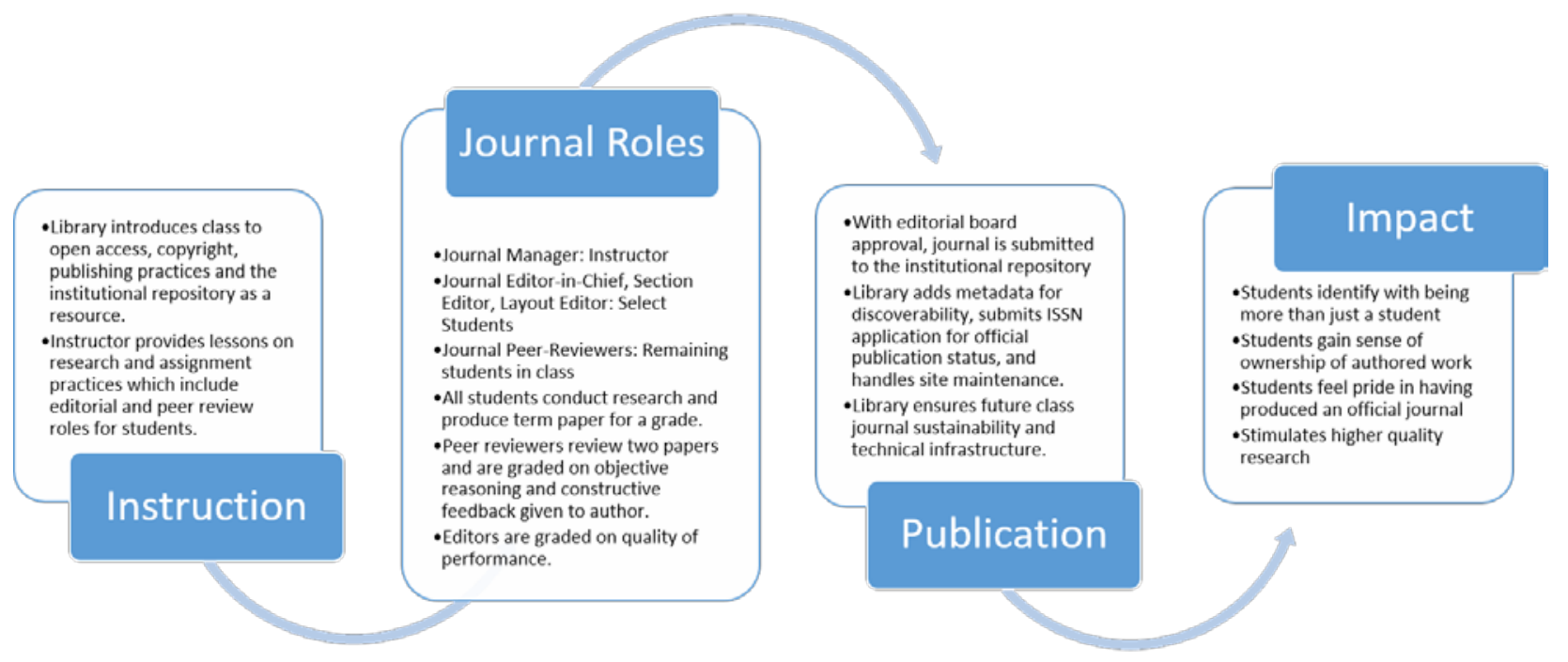

\section{References}

Ellison, N. B. and Wu, Y. (2008). Blogging in the classroom: A preliminary exploration of student attitudes and impact on comprehension. Journal of Educational Multimedia and Hypermedia, 17 (1), 99-122.

Ho, A. K. (2011). Creating and hosting student-run research journals: A case study. Partnership: the Canadian Journal of Library and Information Practice and Research, 6 (2).

Matty, D. J. (2005). Course-based undergraduate research; design considerations. Monograph from Geological Society of America, 2005 Annual Meeting, Salt Lake City, UT. Geological Society of America (GSA): Boulder, CO. October 2005, Vol. 37, Issue 7, pp.343.

November, A. (2010). Empowering student and technology ( $2^{\text {nd }}$ ed.). Thousand Oaks, CA: Corwin.

Stone, G., Jensen, K., and Beech, M. (2016). "Publishing undergraduate research: Linking teaching and research through a dedicated peer-reviewed open access journal." Journal of Scholarly Publishing. University of Toronto Press, 47 (2): 147-170. Doi: 10.1353/scp.2016.0007 